\title{
How to teach engineers to interact in a political decision making environment
}

\author{
Mireia López Royo, Unesco-IHE, Delft, Netherlands (Offshore Independents) \\ Madelon Burgmeijer, Delft University of Technology, Delft, Netherlands \\ Henk Jan Verhagen, Delft University of Technology, Delft, Netherlands
}

\section{Introduction}

Sectoral professionals, like coastal engineers, need to know how to cooperate in a multidisciplinary environment, as well as how to present substantial information to (political) decision makers. In order to train (coastal engineering) students in this matter, Unesco-IHE and TU Delft have in their curriculum an Integrated Coastal Zone Management Seminar. Because there is also a demand for such a seminar from outside the normal student population, this seminar is also open for external participants, like tourist resort developers, ecologists as well as policy support officials, who are in need to learn how to present to decision makers the various development options in a coastal zone.

This paper will give an overview of the nearly 25 years of experience we have collected in giving this seminar in Delft and Overseas. It is written from the learning perspective of a professional who attends the ICZM Seminar, while remarking the challenges and goals expected to be achieved.

\section{Broadening professionals 'minds}

As pointed out in the previous paper Training of coastal engineers to work in a nonengineering environment (Burgmeijer et al., 2011), ICZM is not really a science, but a matter of good cooperation in planning and decision making. The intention of the seminar is therefore to focus on the process of decision making in the coastal zone and on how important communication and interaction between stakeholders are when making the final decision. A conclusion the participants should get to should be that due to the weight of non-technical arguments in the political discussion, what seems to be the "best" solution to solve a specific problem from an engineering perspective is not always the chosen alternative by the ones who have to decide. 
Strange as it may seem, engineers are not taught how to tackle this kind of situations, they are only trained to find the best solution from a technical point of view. In the seminar it is said that they should be trained also as decision makers or be given the tools to participate in the decision making process, as in many developing countries engineers are in charge of taking the decisions as well as finding the technical optimal solution to a problem.

Hence, along the seminar technical lectures are combined with interactive activities and followed by a role play that immensely helps in accomplishing the main goal.

The seminar succeeds in broadening the minds of engineers and the other involved professionals so that they are taught not to only tackle the situation from an engineering perspective, as suggested previously, but to also be capable of understanding the implication of other sectors and cooperate with them to achieve the "best" solution for the given situation. The multicultural environment in the class is also decisive in achieving the established goal of the seminar, as interacting with people from other countries may help in widening one's mind even more. Each one's expertise and professional experience are for sure helpful in that respect.

Since all attendants have a good knowledge of the physical processes in the coastal zone, there is no need to go into much detail in these matters, because the main line of the seminar is the process of decision making in the coastal zone. However, the technical lectures addressing important topics are also valuable for professionals in this sector. Two of the specific lectures in this seminar are about setback lines and climate change effects on the coast, but other important topics are addressed, such as policy analysis, and ecology in the coastal zone among others. In both lectures a direct link can be given between the technical aspects and the implications for decision makers. Also a lecture on ecosystem services can be considered as a "technical lecture", as it emphasizes the services that coastal ecosystems provide to people, which can be material but also non-material and which can be classified into different groups.

The process of Integrated Coastal Zone Management is explained in general terms and it is pointed out that it should be cyclic, starting by an identification of the main issues, a preparation of a program, a formal adoption and funding, its implementation and a final evaluation, which leads at the same time with the beginning of the cycle (identify-implementevaluate-identify). Development of the ICZM plan must take into account the long term goals but also the short term ones. Figure 1 shows the ideal development of an Integrated Coastal Zone Management Plan. 


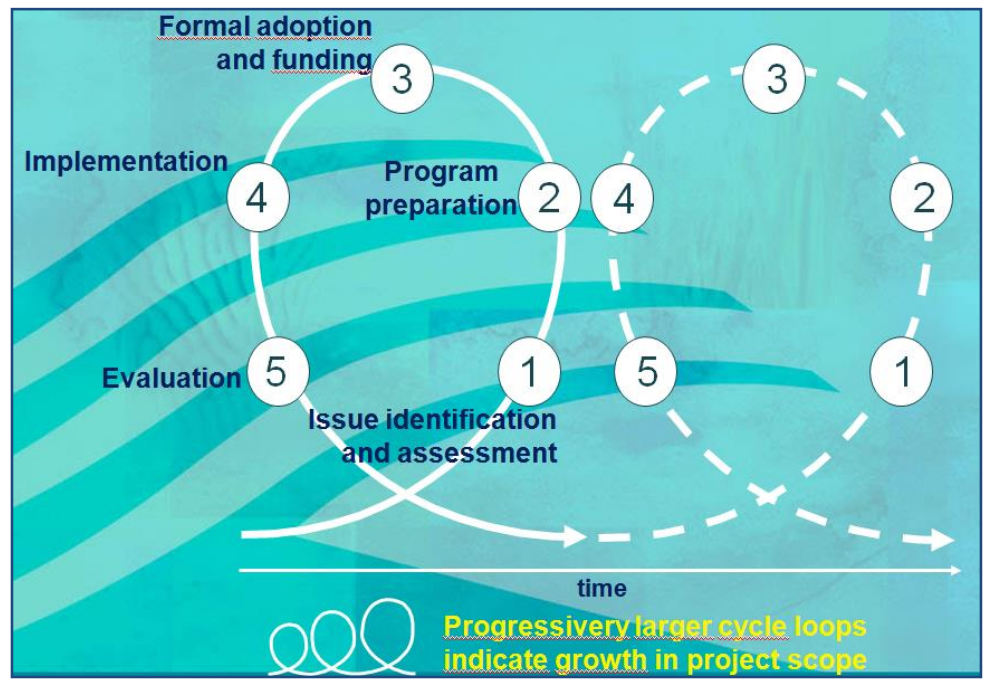

Figure 1. Integrated Coastal Zone Management cycle. (UNESCO-IHE)

In this cycle, public participation should take part in the early stages of the project. Otherwise it might happen that the achieved engineering solution cannot be put into practice due to the final public opposition.

\section{First-hand expert knowledge and experiences}

As it has been already mentioned, in order to provide the best seminar possible several guest speakers are invited to give some lectures. These guests are experts in their fields and provide, by means of examples and study cases from personal experience, valuable knowledge for professionals of the field.

A very specific lecture is on "Building with nature" that presents a twist towards a more nature-friendly and conscious approach of coastal engineering projects. Through a series of case studies, the guest speaker provides examples of a successful implementation of the exposed approach, which may serve as an inspiration for the attendants of the seminar in their future professional challenges. But apart from the fact that the lecturer in this case is quite knowledgeable on the topic, he has a political background. Therefore his lecture is a good starting point for several discussions with the student.

The decision making process is approached by lectures on "Game theory" and "Policy Analysis". They give useful tools for taking decisions. As illustration a number of case studies are discussed with the students. Other guest lecturers present case studies that illustrate either successful or unfortunate examples of existing situations of other related relevant topics in the coastal zone in order to teach a lesson from experience. With the help of these several case studies this working cycle is exposed. Such are the examples of the Case study in Mozambique, in Japan (tsunami), and Spanjaards dune, hedwige polder, and the port of Rotterdam (sustainable expansion).

The lecture about socio-economic aspects of ICZM points, among other things, that the gender aspect may be present. The lecture combines scientific knowledge with non-scientific facts that are certainly involved in the process. 


\section{Main outcome from the fieldtrip}

From the experience of a student who attends the seminar, the fieldtrip is as important and instructive as the lectures, as what one sees in the fieldtrip complements totally to what is learned in the lectures that precede the fieldtrip.

In the last edition of the seminar the one-day fieldtrip consisted in visiting the border that separates the Dutch coastline from the Belgium coastline and noticing how a different management can make two similar coastlines look completely unlike due to different kinds of management. The consequences of these different approaches are visible and may lead to complete different risk exposures, such as the risk to inundation of the Belgium coast, for example.

The fieldtrip contributed together with the role play to make students interact with each other all the time, and it was a first fruitful step to carry on some networking among the participants, which would be very useful for the following activity.

\section{Role play- step by step}

The role play is the key part of the seminar as it certainly triggers the successful achievement of the main goal. Although the role play itself is held in the last two days of the seminar, there are several activities before it starts that are directly related to it and which outcomes are used in the main part of it.

Jesew, a computer program for "Joint Ecological and Socio-economic Evaluation of Water resources development (Zitman, 2003), is rewritten as a spreadsheet application and it is used as a first step to help students elaborate a report they have been hired to do as consultants for a certain client with very specific interests. The main task of each group is to assess the client on how to invest the money available and set a strategy on employment, income, pollution, ecological quality, etc. to find the optimum solution. The assignment that every group gets is basically the same, with the difference that each report has to be done for a different clientwho is a stakeholder of the coastal zone, and therefore the objectives of each one of them are different.

In the second phase roles are changed, as well as groups, and students play each one a role as a stakeholder in the decision making process (one can be the Mayor of the town, the Minister of Finance, the representative of the fishermen, etc.). The role each one represents is given a list of the main interests to care for and a report made by a consultant (reports from the previous activity made by another group; one cannot receive his own assignment), and with this indications he/she has to work to achieve their accomplishment. During the discussions the strengths and weaknesses of the participants are uncovered as well as the quality and usefulness of the reports previously made by others. This has a clear impact on the results of the role-play and the decision taken by the stakeholders involved.

One of the main goals of this role play is to acclaim the similarities with the real situation by, for instance, not giving time to think- as politicians receive reports on their way to a meeting 
where a decision needs to be taken, with just the sufficient time to read it. The reports are supposedly done to fulfill the requirements of each client so each stakeholder should treat each report like self-made. The pressure each stakeholder makes in the decision process is decisive.

Needless to say, decision making is very expensive in real life, as many hours from stakeholders have to be paid. An example of how much the cost of such a process can represent in a project is a total of the $0.5 \%$ of it.

One important remark is that the groups are intentionally designed as multicultural as possible and coordinators try not to put friends in the same group, with the clear intention of promoting interaction and performing the real situation as close as possible.

The final part of the role play consists of discussions and making a decision with all the stakeholders involved in a group. The process itself is closely observed by the coordinators as it is recommendable that certain behaviours are avoided, such as the philosophy "one man, one vote". The process needs to involve all stakeholders, who are invited to give their opinion and propose a strategy. One other significant remark is that is it always easier to convince other stakeholders if one's strategy involves investments in different sectors and therefore benefits others apart from oneself.

In the role play it is important to analyse to what extent the consultants 'reports are being used by the clients who paid for them, and how much the clients believe in them, and make of them their own stance.

The decisions taken are influenced by the personality of the different stakeholder's, as if a certain stakeholder was represented by someone else, the way this person interacts with the other stakeholders might be different and so the decision making process might lead to another result.

The daily press is delivered by the organisers of the seminar with the clear intention to alter the decision making process by inventing some breaking news that could also happen in reality if that was the case. Under these unexpected events the participants of the seminar tend to act the same way- although it is important to remark that sometimes, due to the great persuasive attitude of some participants, this bad news do not affect the sector they are representing, even if it is damaging for many other sectors. This happened in one of the groups in last year's edition of the seminar. On the other hand, even the green associations in favour of a sustainable development might not get the necessary amount of money if that certain person does not make himself/herself heard in the decision making process.

Each coastal zone, however, might have different stakeholders and therefore the management of the coastal zone, despite following the same guidelines and practices, may lead to completely different developments on the coastal zone and a result its appearance look completely different. Moreover, the boundary conditions from one region to another define each specific case. 


\section{Lessons learned}

One of the main lessons a participant can learn from this seminar is the importance to broaden his/her perspective and comprehend a problem in the coastal zone as a multidisciplinary matter involving a series of stakeholders, some of which may be "non-professional", which refers to groups whose main profession is not the management of the coastal zone, like for instance fishermen, but also local politicians.

Year by year the same behavioural pattern is observed by the seminar coordinators, so one could definitely say that the way participants deal with the situation follows the same pattern. However, cultural differences are captured in the role play as the way people from different cultures may deal with negotiations and meetings might be quite different.

On the other hand, the seminar is very useful for participants to note the similarities that the real situation has with the activity they are confronted with, as there is not much time to think, some external influences or news might suddenly change the situation completely and the consultancy report is their main source of information for either taking the decision or supporting one. This so called consultancy report has therefore to be produced in an appropriate way, one which can easily be understood and visually apprehended.

\section{Conclusion and recommendations}

The main goal of the seminar, which is training engineering students to focus on the fact that other disciplines may add useful additional material for decision makers but also broadening their minds, is highly achieved mainly due to student's implication in the role play. The fact that it is so interactive and well-structured makes it even more easy and interesting to follow.

From a student's point of view, the seminar is structured in such a way that it becomes clear what is required in many situations on a professional career such as in decision making processes. There is not the pressure of an exam but it is a continuous personal challenge of having to interact with other students while defending one's interests to others and trying to make them support one's own plan.

This seminar has been inspiring other universities to come and further develop it, which is for example the case of Vietnam.

A recommendation for a further improvement of the seminar is the introduction of the Integrated Water Resources Management (IWRM) concept aligned with ICZM. Participants should get the idea that what happens upstream in a river influences that happening downstream and entering the sea. Rivers flow into the sea and it seems quite obvious that the fact that they carry less or more sediments, and changes in this particular load, will influence the morphology of the coastline, caused by, for instance, the construction of a dam. So the seminar itself should not need to be modified but it would be interesting to reflect this reality and introduce the concept of IWRM.

To sum up, it is all about changing the perspective and learning that to achieve a proper coastal zone management not only scientific and technical knowledge are important, but also 
being able to interact with other stakeholders and parties, as that is actually a significant part of the process.

\section{References}

Burgmeijer, M.A.; Verhagen, H.J.; Van der Wegen, M. (2011) Training of coastal engineers to work in a non-engineering environment. Coastal Management 2011: Innovative Coastal Zone Management: Sustainable Engineering for a Dynamic Coast, Belfast, UK.

Zitman, T.J. (2003) Jesew user guide, TU Delft report 